\title{
SOBRE A ELABORAÇÃO DAS NORMAS JURÍDICAS
}

\section{REGARDING THE PROCESS OF MAKING LAWS}

Taka Oguisso *

Maria José Schmidt*

OGUISSO, T.: SCHMIDT, M.J. Sobre a elaboração de normas jurídicas. Rev.Esc.Enf.USP, v.33, n.2, p. 175-85, jun. 1999.

\section{RESUMO}

Este trabalho apresenta uma sintese simplificada do processo de elaboração de lei, a partir de sua conceituação juridica, requisitos, hierarquia das normas, etapas da tramitação nas chias casas do Congresso Nacional, necessidade de quorum e sanção presidencial até um projeto de lei ser transformado em lei. Tem por objetivo auxiliar os enfermeiros e outras pessoas interessadas no assunto a participar no desenvolvimento de sua profissão através de leis que atendam melhor aos interesses profissionais da. classe.

UNITERMOS: Legislação de enfermagem.

\begin{abstract}
This paper presents a simplified summary of the process to make laws. It starts from the juridical concepts, requirements needed, hierarchy of the Brazilian laws, the need to follow proper steps through channels and committees within. the National Congress, quorum required until its final approval with the presidential sanction, when a project of law becomes an enacted law. The purpose is to help nurses anal other interested people to participate in the development of their profession. through, laws which better fulfill the professional interests of the group.
\end{abstract}

UNITERMS: Legislation nursing.

\section{INTRODUÇÃO}

Todo comportamento humano está sujeito a determinadas regras, criadas pelo próprio homem, para manter o equilibrio das relações entre os homens na sociedade. Tais regras ou obrigações são denominadas leis que, em seu conjunto, formam a legislação. A Enfermagem como todas as demais profissões de livre exercício no país, está regulamentada por leis ou normas jurídicas. Essa realidade tem obrigado os enfermeiros em geral a se interessarem pelo estudo da legislação. A importância desse estudo justifica-se, portanto, pelos seguintes motivos:

- é por via da legislação que se criam ou se extinguem direitos e deveres:

- "ninguém se escusa de cumprir a lei, alegando que não a conhece" é o que está disposto no Código Civil Brasileiro, art. $3^{\circ}$;
- esse dispositivo do Código Civil é ratificado pelo Código Penal art. 21, que estabelece que "o desconhecimento da lei é inescusável. O erro sobre a ilicitude do fato, se inevitável, isenta de pena; se evitável, poderá diminuí-a de um sexto a um terço";

- o estudo da legislação específica pelo próprio profissional favorece uma melhor e maior participação dos enfermeiros no desenvolvimento da Enfermagem.

Assim, as legislações civil e penal brasileiras adotaram o princípio da indesculpabilidade, isto é, não se pode descumprir uma lei por desconhecê-a. No caso do Código Penal acima citado, o erro é considerado evitável se o agente, ao praticar o ato ilicito ou se omitir diante de um dever, o fizer sem consciência ou conhecimento de sua ilicitude, quando, na verdade, "1he era possivel, nas

\footnotetext{
* Enfermeiras e advogadas. Docentes da Escola de Enfermagem da Universidade de São Paulo.
} 
circunstâncias, ter essa consciência". Quando é totalmente inevitável ter conhecimento de que um fato é ilícito, não existe crime e nem penalidade.

\section{CONCEITO JURÍDICO}

A palavra lei é usada na linguagem corrente e científica com um sentido muito amplo: o e um principio que determina não só as ações humanas, como também os acontecimentos naturais. Segundo FRANÇA ${ }^{3}$ (1997), nesta acepção ampla, o conceito de lei dimana da idéia de ordem, isto é, a disposição de seres em função de um objetivo que lhes dá unidade. É possivel, pois, falar em lei natural e lei positiva, lei divina e lei humana, lei física, lei ética e jurídica, lei matemática, etc. Todas essas expressões têm em comum a idéia de que algo ocorre em conseqüência de um princípio, como expressão de relações entre seres da natureza ou como expressão da vontade dos homens.

Em sentido jurídico, ainda segundo FRACA ${ }^{3}(1977)$, a lei assume especial significado no universo do direito, quando indica uma de suas formas de expressão, a mais importante fonte do direito na civilização ocidental. Lei é, então, o direito conscientemente elaborado por uma autoridade, mediante um ato de vontade, o qual se denomina legislação, ou seja o ato de elaborar leis, e consiste numa declaração jurídica revestida de forma escrita e incorporada num documento.

Também pode-se definir lei como a norma ou regra jurídica. escrita e obrigatória, por mais restrito que seja o campo e sua aplicação: emanada de quem poder ou pessoa investida e autoridade - possa garantir ou assegurar essa obrigatoriedade: com vigência por determinado espaço de tempo numa certa coletividade ou grupo social.

A lei carrega em si mesma a sanção, isto é, uma força de obrigatoriedade, que induz ao seu cumprimento. E assim, por excelência, manifestação e poder. Esse poder, originário cio grupo social como um todo, se traduz no Estado, pela soberania, ou seja o exercício de um arbítrio nos limites de um território e sobre todos os seus habitantes.

É a lei que institui a ordem jurídica. Jurídico vem de ius, juridicus, direito e dicere, dizer. A qualidade de jurídico exprime o sentido de legítimo, legal ou justo segundo as circunstâncias em que é aplicado, ao mesmo tempo em que revela o ato ou tudo o que se apresenta apoiado na lei ou no direito. Os parâmetros estabelecidos nas normas legais têm por objetivo oferecer proteção, não só aos que exercem a atividade, mas também s pessoas a quem essa atividade é dirigida.
A organização política de uma sociedade está baseada na ordem jurídica instituída pela lei, como um meio para manter o equilíbrio entre as relações do homem na sociedade (Anexo 1), no tocante a seus direitos e deveres. Como se vê, a família é a base de qualquer sociedade, como a "menor democracia no coração da sociedade", segundo o emblema do Ano Internacional da Família, celebrado em 1994, pelas Nações Unidas ${ }^{6}$. E na família que o indivíduo deve encontrar vida e amor, calor humano, proteção, segurança, convivência, tolerância e aceitação. O conjunto de famílias irá formar os agrupamentos sociais e assim sucessivamente até formar a nação organizada.

Nessa ordem jurídica está assentado também o conjunto de regras obrigatórias, formulado para proteção de todos os interesses e para norma de conduta de todas as ações; e, porque são estabelecidas pelo próprio homem, impondo-se ao respeito e obrigatoriedade de todos, diferenciam-se das leis naturais 5 .

As leis jurídicas caracterizam-se essencialmente pela sua generalidade ou universalidade e obrigatoriedade.

$\mathrm{O}$ caráter de generalidade evidencia-se no princípio de que as leis não se estabelecem ou se prescrevem para cada pessoa, mas sim, para todos em geral. A obrigatoriedade da lei decorre da própria ordem jurídica pré-existente e firma-se na sanção ou coercibilidade imposta para fazer valer a regra que nela se institui.

A inflexibilidade da lei em relação sua obrigatoriedade e generalidade está demonstrada no aforismo dura lex, sed lex, isto é, a lei é dura, mas é lei. Quer isto significar que a lei deve ser obedecida, não importando a regra que venha a instituir ou o principio que venha a estabelecer. Deve visar o bem comum e não impor regras ou normas absurdas.

Semelhante assertiva, entretanto, não significa que qualquer disposição possa ser imposta pela lei. Esta há que obedecer aos princípios da ordem jurídica, sem impor regras ou normas irregulares e absurdas, que fujam aos fundamentos o próprio direito, firmados em seus preceitos naturais. Portanto, as leis devem à sempre visar o bem comum e atender às exigências e necessidades do homem, com base nas exigências da natureza ${ }^{5}$.

\section{OS TRÊS PODERES}

O Brasil como todo país democrático, exerce sua soberania através de três poderes: o Legislativo, o Executivo e o Judiciário. O Poder Legislativo em nivel federal ou nacional é exercido pelo 
Congresso Nacional, que é formado pela Câmara dos Deputados e pelo Senado Federal, que se complementam. Os deputados federais são representantes do povo eleitos para mandatos de quatro anos pelo voto proporcional** em seus respectivos Estados de origem e os senadores, para oito anos, em número de três cada Estado e para o Distrito Federal, pelo sistema majoritário*** independentemente da população existente. Em nivel estadual é exercido pela Assembléia Legislativa em cada Estado, composta por deputados estaduais e em nível municipal pela Câmara Municipal, composto e vereadores.

O Poder Executivo **** com a função de administrar a nação, em nivel federal, é exercido pelo presidente da República, eleito pelo sistema majoritário e assessorado por ministros de Estado (atualmente 29). Pode construir escolas:hospitais, rodovias ou ferrovias e com autorização do Congresso pode declarar estado de sitio, de emergência e guerra. 0 governador em cada estado, assessorado pelos secretários, administra o Estado. O prefeito, auxiliado também pelos secretários, administra o município.

O Poder Judiciário tem a função de decidir sobre a aplicação das leis e é exercido pela magistratura e ministérios públicos em duas ou mais instâncias conforme mostra o quadro (Anexo 2), tendo em sua base as Varas Cíveis ou Criminais, as Juntas de Conciliação e Julgamento, juizos federais, militares. etc. O órgão máximo do Poder Judiciário é o Supremo Tribunal Federal. Na Justiça Estadual existem as Varas Civeis e Criminais em primeira instância e os respectivos 'Tribunais de Justiça Estadual e o Superior Tribunal de Justiça. Na área federal, existem os Juízos Federais, também com suas Varas Cíveis e Criminais e em segunda instância os Tribunais Regionais Federais. Na área trabalhista, a primeira instância é constituída pelas Juntas de Conciliação e Julgamento e em segunda instância pelos Tribunais Regionais do Trabalho. Na Justiça Eleitoral também existem as Juntas Eleitorais e os Tribunais Regionais Eleitorais. A Justiça Militar pode ser estadual ou federal, cada um com os respectivos órgãos de auditoria em primeira instância, seguidos dos Tribunais da Justiça Militar. Havendo matéria de âmbito constitucional, de qualquer uma dessas áreas, os processos são encaminhados para o Supremo Tribunal Federal.

O Congresso Nacional, que tem a função de criar leis de interesse de toda a nação e de fiscalizar a atuação do Presidente da República, aprecia os projetos apresentados pelos seus parlamentares, pelos representantes dos tribunais federais, pelo presidente da República e por projeto de lei de iniciativa popular.

A sociedade pode, portanto, diante de alguma necessidade sentida, encaminhar reivindicações aos seus representantes no Legislativo, que elaboram os projetos de lei. Os projetos de lei apresentam uma ementa que informa o assunto principal do projeto, uma parte introdutória e disposições gerais ou preliminares além das transitórias ou finais. Devem ser redigidos de tal forma que contem com uma sistematização dos assuntos por títulos. Cada título deve ser subdividido em capitulos e, estes, em seções. As unidades são apresentadas em forma de artigos e parágrafos, em números arábicos ordinais do primeiro ao nono e em seguida por números cardinais. O parágrafo tem caráter assessório, elucidativo do texto principal do artigo. Ambos, artigos e parágrafos, podem ser desdobrados em incisos e alíneas. Não sendo parágrafo único, eles podem ser representados por um sinal gráfico especial (§). Cada inciso é numerado por algarismos romanos e as alíneas por letras minúsculas. Quando apresentados, os projetos são acompanhados de uma justificativa e se a proposta foi feita pelo presidente da República estará acompanhada de uma mensagem.

\section{A ORGANIZAÇ̃O DO CONGRESSO NACIONAL}

Cada uma das casas do Congresso' tem uma Mesa Diretora, uma Comissão de Constituição e Justiça $(\mathrm{CCJ})$, comissões permanentes e temporárias. Além da CCJ, a Câmara tem mais doze comissões permanentes, entre elas a de Ciência e Tecnologia, Defesa do Consumidor, Direitos Humanos, Educação, Seguridade Social e Família, e Trabalho que são as que podem ter maior reação com o ensino e o exercício da Enfermagem. Já o Senado tem outras seis comissões permanentes: assuntos econômicos, assuntos sociais, educação, relações exteriores, defesa nacional e de infraestrutura. As comissões permanentes são organizadas de acordo com a proporcionalidade dos partidos, mas também seguem critérios políticos e técnicos, pois os membros da comissão devem ter em sua formação ou experiência alguma afinidade com o assunto em pauta. As comissões temporárias

\footnotetext{
** Estados mais populosos elegem mais representantes, dentro de um mínimo de oito e Maximo de 70 por

*** Estado. O partido político mais votado tem direito a preencher mais vagas.

**** COMO funcionam o Legislativo e o Executivo. O POVO, Fortaleza, 4 set.1994. p.3F Caderno F, Supereleiçoes.
} 
tratam de um tema especifico, como, por exemplo, a comissão parlamentar de inquérito (CPI) ou uma comissão destinada a representar a Câmara ou o Senado fora da sede do Parlamento.

\section{HIERARQUIA DAS NORMAS}

A hierarquia das normas (Anexo 3) resulta basicamente da posição que as normas ocupam, com uma reação de superioridade e inferioridade entre elas. Assim, as leis são válidas porque se apóiam em outras que lhe são hierarquicamente superiores. Essa disposição hierárquica das normas prevê em principio três planos: o constitucional composto da Constituição e leis complementares à Constituição; o ordinário com as leis ordinárias; e o terceiro plano com os regulamentos ${ }^{1}$.

A Constituição é a lei suprema, estabelecida pelo povo em virtude de sua soberania para servir de base à sua organização política, dispor sobre os modos de criação de outras leis e estabelecer direitos e deveres de seus membros.

As leis ordinárias são normas elaboradas pela autoridade investida de poder legislativo.

Finalmente, os regulamentos e resoluções são regras ou disposições estabelecidas para que se executem as leis, e são elaboradas por autoridades que recebem das leis constitucionais e ordinárias a competência ou o poder. administrativo. Existem ainda os regimentos que dispõem sobre a organização e funcionamento interno de um órgão público ou privado.

Portanto, a hierarquia das normas mostra que existe uma ordem de grandeza condicionando inclusive o espaço de aplicação, a menor ou maior abrangência da generalidade dos cidadãos. Nesse caso. na base dessa pirâmide podem ser incluídos os contratos que têm força de lei entre as partes contratantes e também as sentenças judiciais que tem menor abrangência de todas as normas por serem aplicadas pelo juiz a um determinado cidadão. .Acima de todas, está a lei constitucional, vigente nos limites totais do Estado, para todos os indivíduos, acima de todos os órgãos da soberania e sobre todos os seus titulares. Portanto, pela sistemática jurídica, a Constituição é depositária da soberania. Não pode o Congresso Nacional, mediante lei ordinária, contrariar dispositivo constitucional. A revogação de um inciso da Carta Magna deverá seguir o rito complexo da própria elaboração constitucional.

De acordo com o texto da Constituição (art. 59). abaixo da Carta Magna ou Constituição estão as emendas Constituição, leis complementares, leis ordinárias. leis delegadas, medidas provisórias,decretos legislativos e, resoluções aos quais podem ser acrescidos as portarias e, por último, os contratos e sentenças, como já referidos.

- Leis complementares à Constituição são as que se destinam a desenvolver os principios constitucionais que não sejam auto-aplicáveis, dependendo de regulamentação que elas consubstanciam. Ex. Lei de Diretrizes e Bases da Educação Nacional. As leis complementares são as que versam sobre matéria de natureza não constitucional, embora devam obedecer aos preceitos constitucionais.

- Leis ordinárias - referem-se a qualquer matéria e sua iniciativa segue o preceito constitucional. Ex. Código Civil, Código Penal, Lei do Exercício da Enfermagem, etc.

- Leis delegadas - eventualmente o Congresso Nacional pode delegar sua função legislativa a uma comissão composta de seus membros ou até mesmo ao presidente da República, sem a participação do plenário. A lei assim elaborada chama-se lei delegada. A delegação ao presidente da República é feita por resolução, especificando seu conteúdo e os termos do seu exercício.

- Medida provisória - ato do presidente da República com força de lei mas que deve ser submetida imediatamente ao Congresso. Se a medida provisória não for convertida em lei no prazo de 30 dias, perde a eficácia, mas o presidente pode reapresentá-la, com ou sem modificações. Houve períodos históricos no Brasil, em que o presidente da República baixava decreto-lei, isto é, norma emanada de Poder Executivo com o conteúdo de uma lei, isto é, decreto com força de lei, excluído atualmente da Constituição do País.

- Decreto legislativo é um ato que visa regular matéria de competência do Legislativo, sem a sanção do chefe do Poder Executivo.

- Resolução é um ato da administração de um colegiado (ex. Conselho Nacional de Saúde, Conselho Federal de Enfermagem) ou uma assembléia, contendo esclarecimentos, solução, deliberação, regulamentação ou determinação sobre algum assunto.

- Portaria é um ato escrito por meio do qual uma autoridade qualquer na esfera dos três Poderes (ministérios, secretarias de Estado, tribunais regionais, autarquias), tais como ministro de Estado, juiz, reitor de universidade, diretor de hospital, diretor de escola e de outra instituição qualquer, determina providências de caráter administrativo, dá instruções sobre a execução de leis ou serviços, nomeia ou designa funcionários e aplica medidas de ordem disciplinar a subordinados que incidam em falta. 


\section{TRAMITAÇÃO E QUORUM}

Três regimes de tramitação podem ser estabelecidos para cada projeto: ordinária (sem prazo para ser apreciado); prioridade (tem preferência para ser colocado na pauta da sessão seguinte); urgência (coloca o projeto na ordem do dia para discussão e votação imediata, se a preferência for aprovada pela maioria absoluta, mesmo que a sessão já esteja em curso).

Cada tipo de projeto requer um tipo de quorum para aprovação em votação. Os projetos de leis ordinárias exigem maioria simples (50\% mais um). Já os que envolvem matéria constitucional exigem quorum de três quintos (3/5) nas duas casas, Câmara e Senado. Todos os projetos precisam ser aprovados pelas duas casas, antes de ir para as mãos do presidente da República.

\section{PROCESSO DE ELABORAÇÃO DE UMA LEI}

A elaboração formal da lei federal no Brasil, dentro do regime bicameral, composto de Câmara dos Deputados e Senado Federal, obedece a dispositivo constitucional (Seção VIII, art. 59ss.) sobre processo legislativo: é matéria de regulamentação interna da Câmara e segue um método ou técnica jurídica.

O texto com teor normativo, que se pretende transformar em lei, antes do início do processo legislativo. chama-se ante-projeto. Denomina-se iniciativa a primeira fase do processo legislativo consubstanciada na apresentação do texto.

O processo ou ritual, que deve ser seguido na elaboração da lei ou norma jurídica, (Anexo 4) aplicase nos casos de emendas à Constituição, leis complementares à Constituição, leis ordinárias, leis delegadas. medidas provisórias, decretos legislativos e resoluções, além de portarias.

Qualquer lei que se pretenda elaborar, mesmo uma nova Constituição, já encontra em vigor um universo de normas legais. Portanto a criação legislativa será sempre um trabalho de complementação, com a finalidade de revigorar a estrutura jurídica, aperfeiçoá-la, suplementá-la, atualizá-la ou conformá-la à evolução social.

A iniciativa de propor projetos de lei ao Congresso pode ser de um parlamentar ou grupo de parlamentares. de uma comissão, da Mesa da Câmara ou do Senado, do presidente da República, dos tribunais superiores, do procurador-geral da República ou dos cidadãos ou grupos de cidadãos, a partir de uma necessidade sentida.
Até que essa necessidade sentida seja estudada por especialistas e interessados no problema e seja proposto um ante-projeto de lei que se transforma em projeto de lei e a seguir em lei há três fases (Anexo 5). A 1a. fase é a do ante-projeto, a 2a. fase é do projeto de lei, quando ele tramita nas duas casas do Congresso Nacional. Ao deixar o Poder Legislativo inicia-se a 3a. fase em que o Projeto de lei irá se transformar em lei. Para tanto, o projeto devidamente aprovado pelo Poder Legislativo será encaminhado ao Poder Executivo para a sanção (ou veto), promulgação e publicação. Ao ser publicado o projeto, já identificado como lei, recebe um numero com a data da promulgação.

Apresentado um projeto na Câmara, ele passa primeiro pela Comissão de Constituição e Justiça, que avalia se fere, ou não, os preceitos constitucionais.

Se aprovado pela CCJ, o projeto segue para uma das comissões temáticas, a que lhe diz respeito, passando obrigatoriamente por uma das comissões permanentes, e s vezes por duas ou mais, de acordo com às áreas $\mathrm{s}$ quais ele se refere, antes de ser submetido à Mesa Diretora. As comissões tem prazos específicos para apreciar matérias em regime de urgência, de prioridade ou de tramitação ordinária. Os membros de comissões podem propor alterações ou emendas aos projetos. As emendas podem ser aditivas, substitutivas ou supressivas. Como o próprio nome diz, são alterações que podem ser acrescentadas ao texto, em forma de novos artigos, parágrafos ou incisos, ou essas alterações implicam na substituição de textos e, finalmente, podem ser suprimidos do texto.

Aprovado pelas Comissões, o projeto segue para a Mesa Diretora da Câmara, que decide quando ele deve ser votado, de acordo com sua ordem de preferência e o interesse dos líderes dos partidos.

Uma vez aprovado na Câmara, o projeto deve passar pelo Senado, onde todo o procedimento se repete: ele é examinado pela CCJ do Senado e pelas comissões permanentes, passa pela Mesa Diretora e vai à votação. Qualquer modificação que o Senado faça no projeto que recebeu da Câmara implica no retorno do projeto para a Câmara, depois de aprovado no Senado, e repita toda a tramitação original. Se não houver modificação, a Câmara o confirma. Se houver modificação na Câmara, ele volta ao Senado e refaz todo o percurso.

\section{SANÇÃO PRESIDENCIAL}

Aprovada nas duas Casas do Congresso, a matéria vai para a sanção ou aprovação presidencial. 
O presidente da República pode acatá-a ou vetá-a. 0 veto é um direito que assiste ao chefe do Poder Executivo de recusar sua sanção ou aprovação votada pelo Legislativo. Caso o presidente considere o projeto, no todo ou em parte, inconstitucional ou contrário ao interesse público pode vetá-lo total ou parcialmente. $\mathrm{O}$ veto presidencial é apreciado pelo Congresso em sessão conjunta, dentro de 30 dias de seu recebimento, só podendo ser rejeitado pela maioria absoluta dos deputados e senadores em escrutínio secreto. Após a sanção, o chefe do Estado promulga, ou seja, reconhece a existência da lei e está de acordo com ela e por isso a faz publicar em diário oficial, o órgão de divulgação do governo. Portanto, a publicação é o último ato do processo de elaboração da lei, que a torna obrigatória por ter início a vigência da lei. Sem publicação não haverá obrigatoriedade de cumpri-la.

\section{CONCLUSÕES}

Como se vê, o conhecimento do processo para elaboração de normas jurídicas constitui realmente objeto de interesse dos profissionais de enfermagem para tornar a profissão socialmente mais reconhecida e valorizada, além de torná-la mais visível, o que em última instância será benéfica para todos, sejam os profissionais ou seja a sociedade que eles devem servir.

As pioneiras da Enfermagem perceberam isso precocemente e assim lutaram por todos os meios para aprovar leis favoráveis à profissão, sabendo que a lei é a mais importante fonte de direito na civilização ocidental, como bem expressa FRANCA (1077). Desta forma, elas pretendiam fazer valer os direitos dos enfermeiros e assegurar o desenvolvimento da profissão e dos profissionais. Em muitos aspectos esse trabalho rendeu os frutos esperados e em outros necessitou continuidade na luta pelas gerações sucessivas e ainda terá que ser continuada pelas gerações futuras de enfermeiros.

Além disso, o art. $3^{\circ}$ do Código Civil e o 21 do Código Penal, ambos citados no início deste trabalho, demonstram o principio da indesculpabilidade na legislação brasileira, embora admita uma graduação de pena e, até mesmo, sua isenção quando o desconhecimento sobre a ilicitude de um fato, é totalmente inevitável. Certamente a formação universitária do enfermeiro não the permitiria alegar desconhecimento como motivo para furtarse ao cumprimento das leis.

Assim sendo estudantes de graduação também devem ser mobilizados desde o momento em que escolheram a Enfermagem como profissão para participarem na vida social e política da enfermagem, através das organizações profissionais da casse, para poder influenciar efetivamente nos destinos da profissão.

\section{REFERÊNCIAS BIBLIOGRÁFICAS}

BRASIL, Constituição, 1988. Constituição da Republica Federativa do Brasil, 1988. São Paulo, Saraiva, 1989.

FRANÇA, R. L.(coord.) - Enciclopédia Saraiva do Direito. São Paulo, Saraiva, 1977. v. 48, p. 430.

OGUISSO, T. Aspectos jurídicos do código de deontologia de enfermagem. Rev.Esc.Enf.USP, v. 13, n.3, p.225-32, 1979

ORGANIZAÇÃO DAS NAÇÕES UNIDAS - 1994. International Year of the Family: Building the smallest democracy at the heart of the society. United Nations, Vienna, 1991.

COMO funcionam o Legislativo e o Executivo. O Povo , Fortaleza, 4 set. 1994. p.2F. Caderno F, Supereleições.

JUDICIÁRIO: estrutura do poder. O Povo, Fortaleza, 4 set.1994. p.3F. Caderno F, Supereleições.

\section{ANEXOS:}

1 - Organização política da sociedade

2 - Estrutura do Poder Judiciário

3 - Hierarquia das normas

4 - Processo de elaboração de uma lei federal

5 - Fases da elaboração de uma lei federal. 


\section{Anexo 1}

\section{ORGANIZAÇÃO POLÍTICA DA SOCIEDADE}

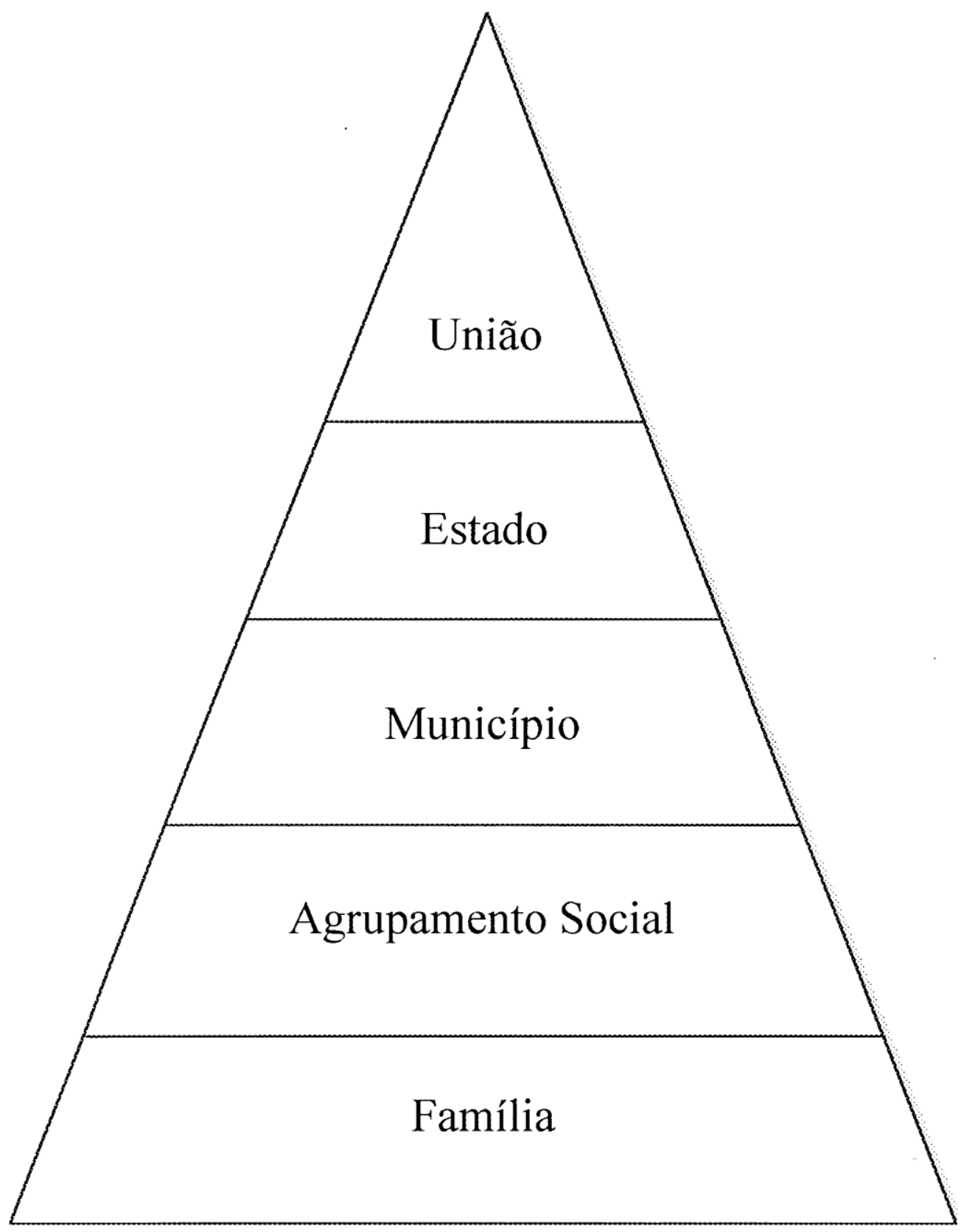




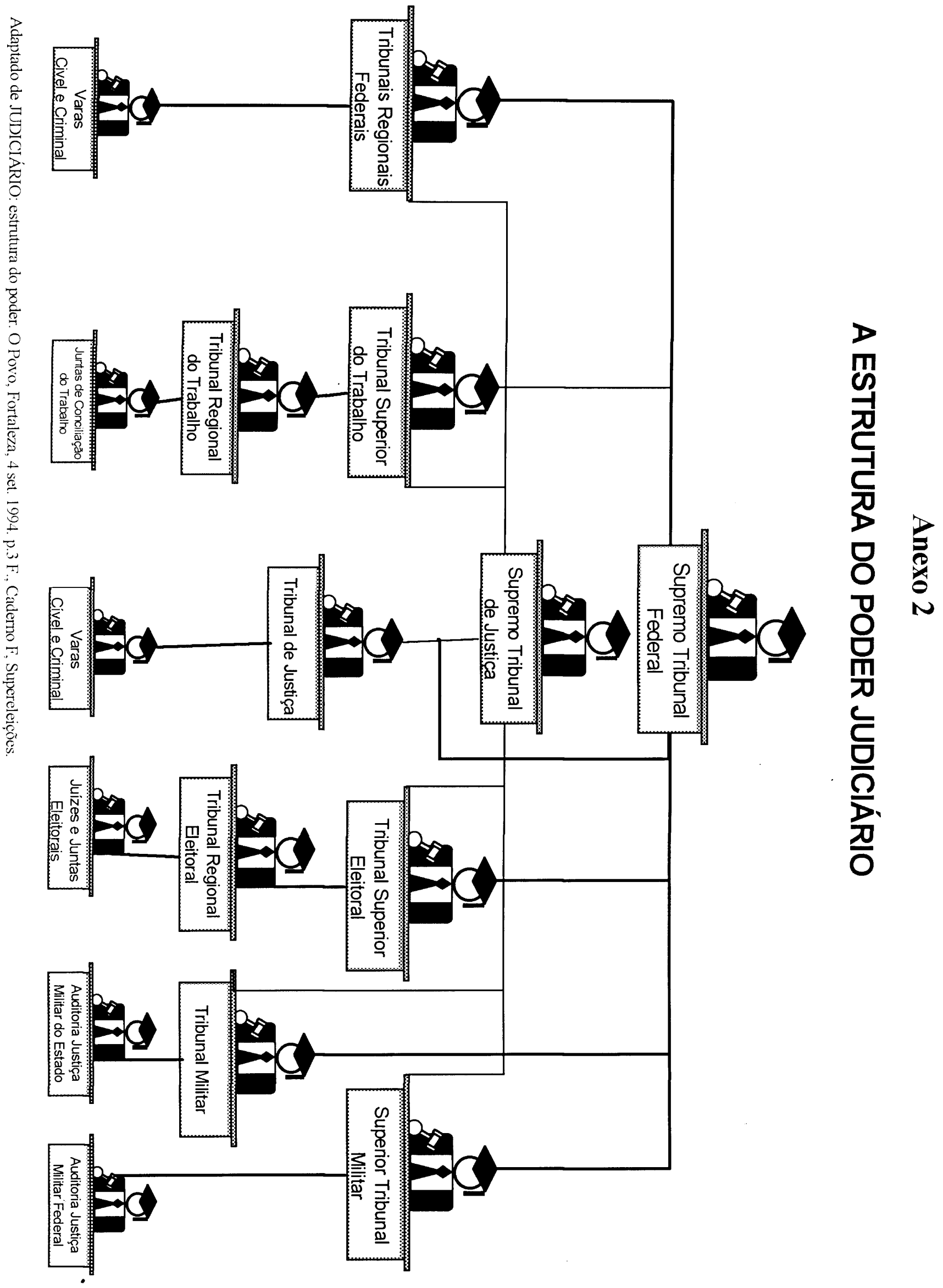




\title{
Anexo 3
}

\section{HIERARQUIA DAS NORMAS}

\author{
TRIANGULO 2
}

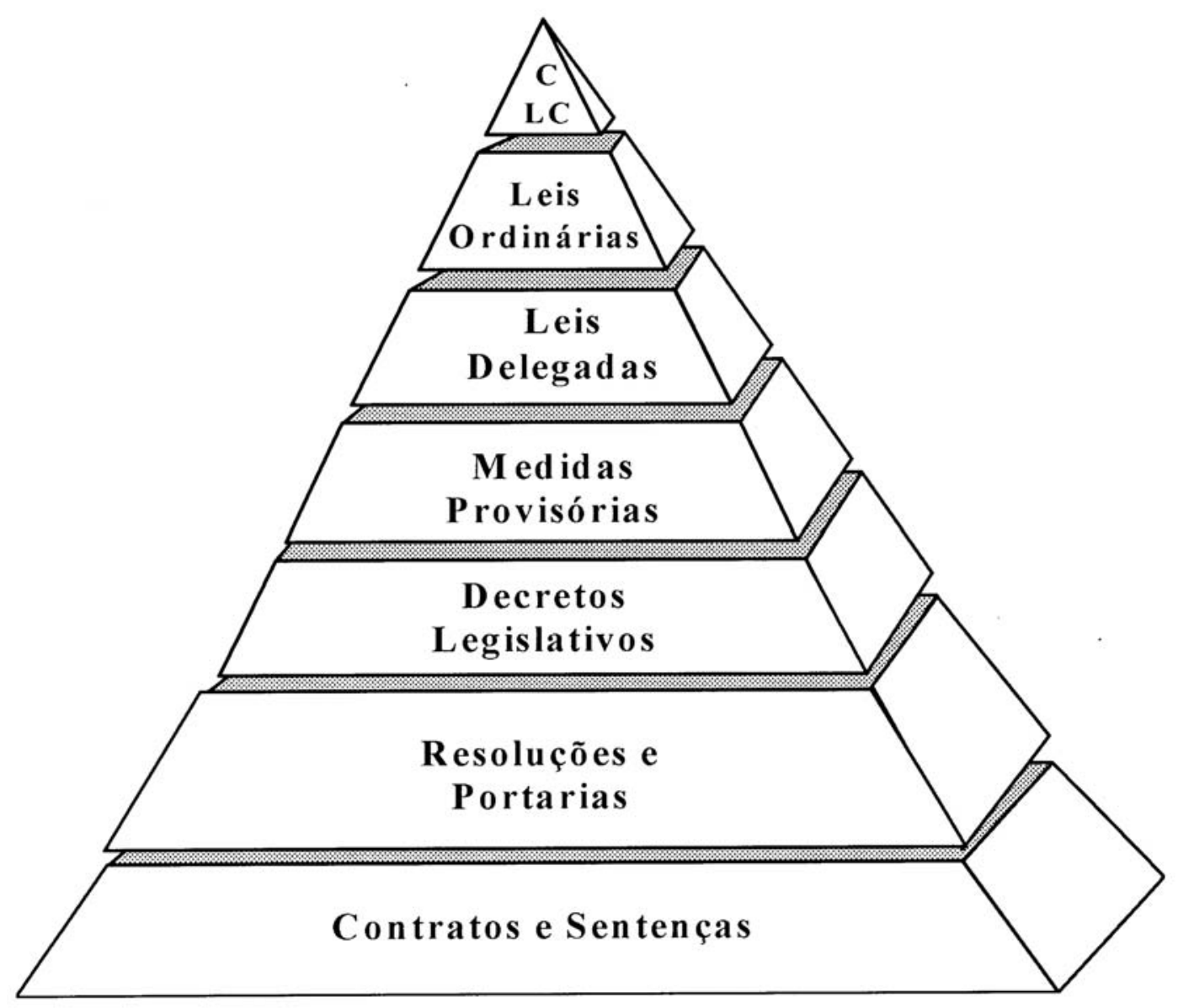



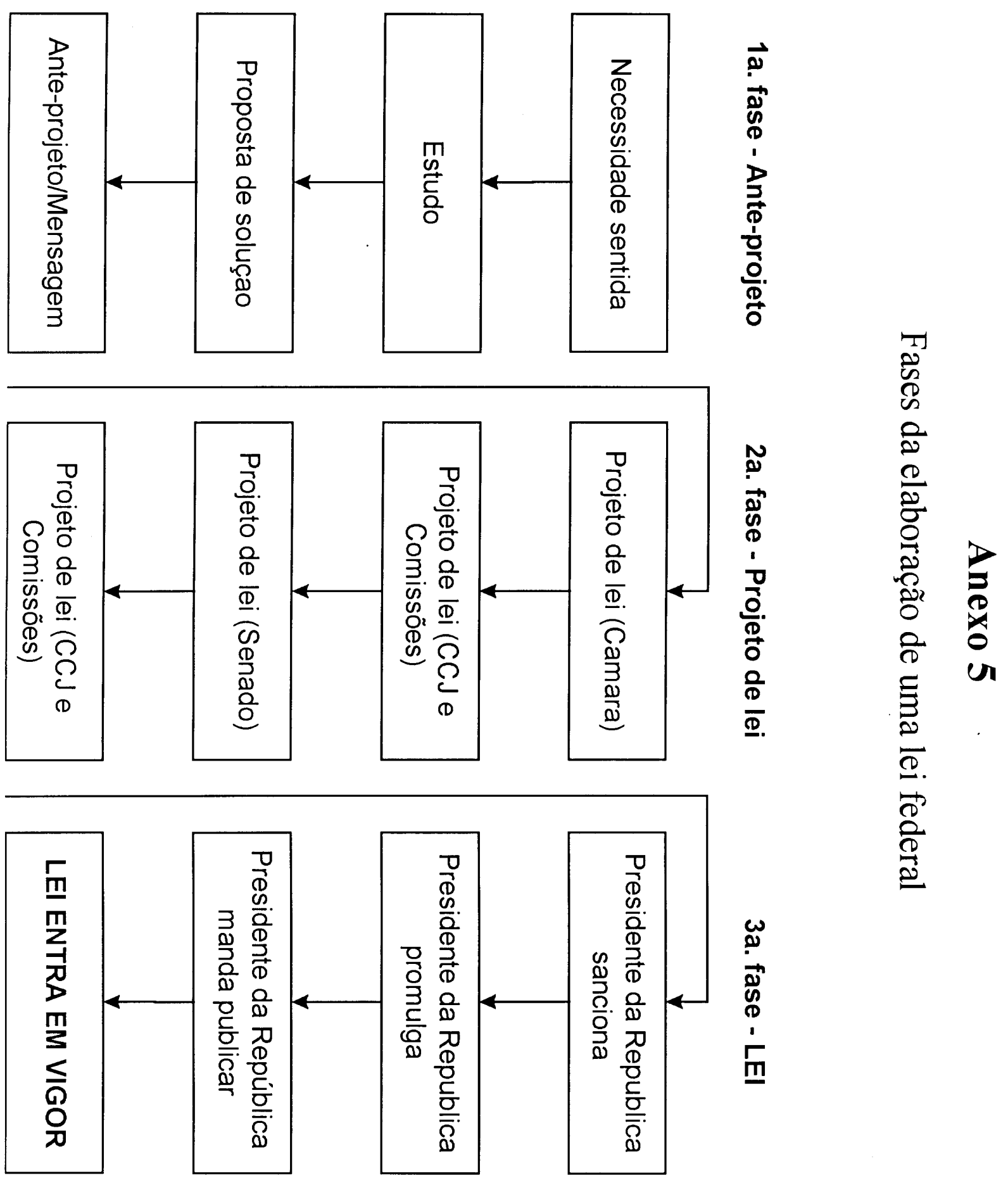

Dि 